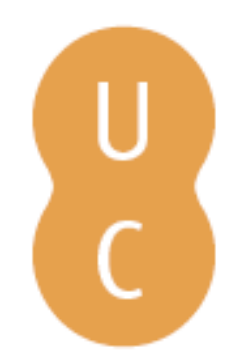

\title{
pompalina
}

\section{NITROFIREX: existing technologies and nighttime aerial firefighting solutions}

Autor(es): $\quad$ M. Bordallo, Luis; Burwitz, Alexander

Publicado por: Imprensa da Universidade de Coimbra

URL

persistente:

URI:http://hdl.handle.net/10316.2/34225

DOI:

DOI:http://dx.doi.org/10.14195/978-989-26-0884-6_161

Accessed : $\quad$ 26-Apr-2023 12:47:34

A navegação consulta e descarregamento dos títulos inseridos nas Bibliotecas Digitais UC Digitalis, UC Pombalina e UC Impactum, pressupõem a aceitação plena e sem reservas dos Termos e Condições de Uso destas Bibliotecas Digitais, disponíveis em https://digitalis.uc.pt/pt-pt/termos.

Conforme exposto nos referidos Termos e Condições de Uso, o descarregamento de títulos de acesso restrito requer uma licença válida de autorização devendo o utilizador aceder ao(s) documento(s) a partir de um endereço de IP da instituição detentora da supramencionada licença.

Ao utilizador é apenas permitido o descarregamento para uso pessoal, pelo que o emprego do(s) título(s) descarregado(s) para outro fim, designadamente comercial, carece de autorização do respetivo autor ou editor da obra.

Na medida em que todas as obras da UC Digitalis se encontram protegidas pelo Código do Direito de Autor e Direitos Conexos e demais legislação aplicável, toda a cópia, parcial ou total, deste documento, nos casos em que é legalmente admitida, deverá conter ou fazer-se acompanhar por este aviso. 


\section{ADVANCES IN}

Forest Fire

\section{RESEARCH}

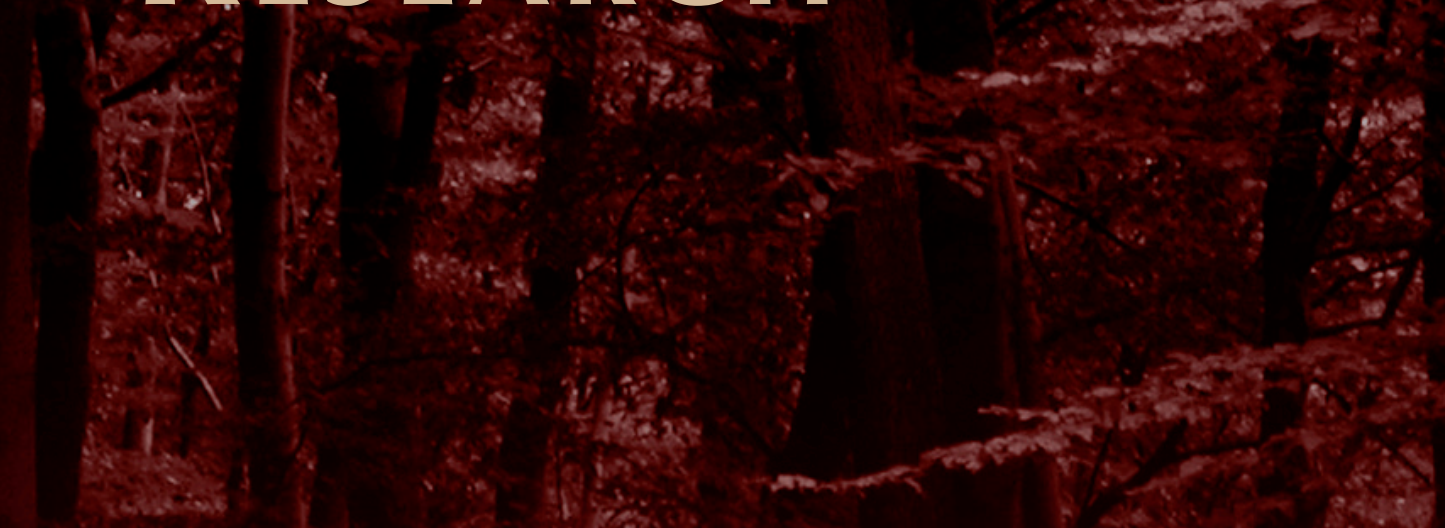

\section{DOMINGOS XAVIER VIEGAS}

\section{EDITOR}




\title{
NITROFIREX: Existing technologies and nighttime aerial firefighting solutions.
}

\author{
Luis M. Bordallo, Alexander Burwitz
}

NITROFIREX ${ }^{\text {S.L. }}$. C/ Islas Baleares 4 Santiago De La Ribera (30720) Murcia Spain. luisbordallo@nitrofirex.com/alexander.burwitz@nitrofirex.com

\begin{abstract}
The maturity of the technologies for the guidance and control of UASs allows proposing innovative operational options such as the ability to spray (a liquid) or spread (a powder) a significant amount of an agent of any sort at a pre-established point in the atmosphere.

This is the case of NITROFIREX, an innovative Spanish project that integrates available technologies from the defense industry to achieve this operational capability
\end{abstract}

Keywords: nighttime aerial fire fighting, new technologies, UAS, launcher aircraft, autonomous gliders containers, risky operation, operative and economical efficiency

\section{Introduction}

It may be the controversial climate change or perhaps human pressure on the natural environment but the fact is that, year after year, alarming reports of devastating forest fires monopolize the media. The past summer of 2012 saw how catastrophic fires razed through the U.S.A., Portugal, Canada and especially Spain and in previous summers how Russia, Bolivia, Israel, California, Australia or Greece stood by helplessly before the devastation of their natural heritage. In the coming years, and this is unfortunately more than likely, we shall have to continue suffering from this modern plague that is ravaging our forests.

In facing this bitter reality it is necessary to ask whether political, economic and technical levels are contributing in finding solutions, or at least methods to efficiently avoid and relieve these disasters. Unfortunately the answer is a very clear and definite negative.

According to estimates from the IPCC (Intergovernmental Panel on Climate Change) forest fires create at least $20 \%$ of all $\mathrm{CO} 2$ projected into the atmosphere annually. On the other hand, all the activity of commercial aviation worldwide causes only $2 \%$ of all the emission.

For example, the European project CLEANSKY has a budget estimated at 1.600 millions of Euros in order to obtain a higher efficiency of engines, the employment of biofuels, intelligent wings and the reduction of weight, etc. Paradoxically, very little technological effort is being put into research regarding the elimination or the reduction of the $14-20 \%$ emission of $\mathrm{CO} 2$ that results from wild fires and, above all, the lack of research into aerial fire extinction - the most versatile and effective method to fight fires.

In the face of the social alarm, political upheaval and vast economic losses engendered by these wildfires, why is it that so few technical resources are available to fight these fires with the greatest efficiency possible? Why, for example, having at our finger tips technology that literally allows us to place a guided bomb carrying 200 or 300 kilos of explosives and fired from a warplane some dozens of miles away through a window (see photo below)... why can't we use the same technology to drop, throughout the night, loads of 2,000 to 3,000 litres of water continuously over a burning forest? 


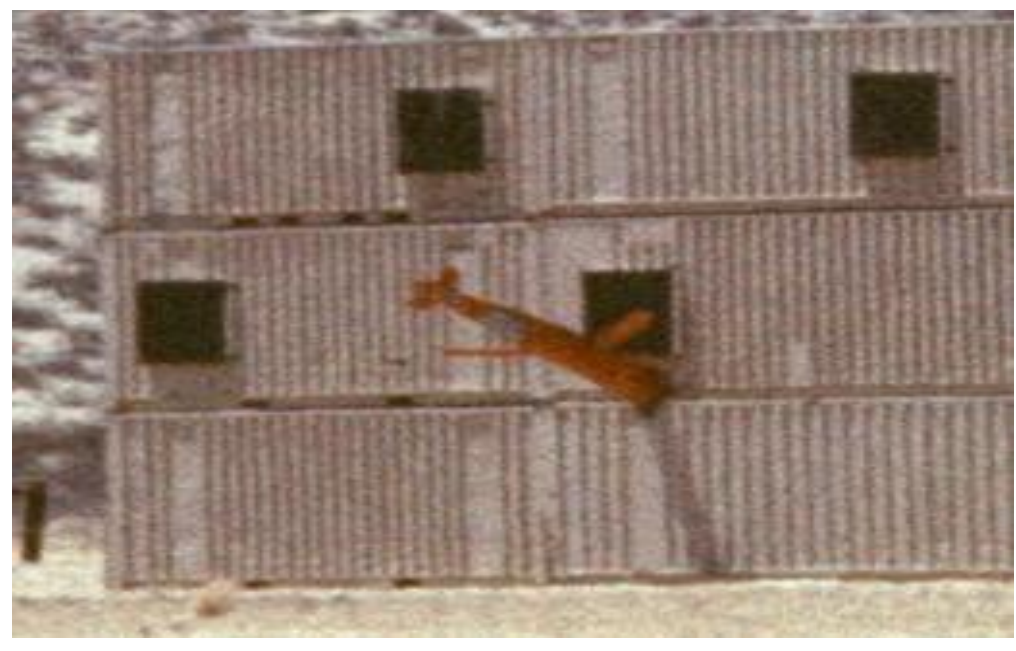

Figure 1

Why is it that an aeronautical sector, which internationally moves thousands of millions of $\$ / €$, is still confined to using methods, techniques and procedures developed some 60 years ago in extreme high risk operations for their crews? Why not integrate available technology and develop the capacity to drop more fire extinguishing agents in less time, but above all, to be able to do so at night. Have we forgotten that the inability to fly at night is the greatest operative lack in present day fire fighting?

\section{State of the art}

The fixed-wing aircraft employed to combat wildfires at present are principally slow-moving turboprops and the majority are planes used exclusively for the job. In isolation and in numerous highrisk operations for crews they visually discharge their loads only between sunrise and sunset.

Apart from the fact that the power plants have changed from piston to turbo, few other technical advances have been applied to the fire fighting fleets since the Second World War. And yet, as we have seen in other fields of aeronautics, the progress has been spectacular.

There is a great concern at the business and academic level to provide answers to the challenge of extinguishing forest fires. In the last decade several solutions have appeared. A good example is the use of huge transport aircraft such as the B-747 Jumbo or DC-10 aircraft, employed by the American Company Evergreen (http://www.evergreen.com), because of their capacity to drop far greater loads of extinguishing agents.

Obviously these aircraft are able to discharge vast amounts of extinguishing agent, but because of their lack of manoeuvrability at low altitudes, their scope of action is greatly reduced. Their excessive length of reaction time and high operational costs render them non-effective in 'first line attack' on the fire. They only become effective once the fire has reached huge dimensions.

But, above all, the use of these big aircraft offers no solutions to nocturnal fire fighting due to their inability to operate visually at night and at low altitude.

Another project also aimed at changing methods and techniques of aerial wildfire fighting is the Precision Container Air Delivery System (PCADS). Supported by Boeing and Weyerhaeuser their method consists of launching, by means of parachutes with no guides of any type, via the rear ramp of heavy-duty transport aircraft a series of biodegradable cubic containers with a capacity of 250 gallons (some 950 litres) each of extinguishing agent from about 500 feet AGL. Once in the air and at about 200 feet AGL these containers open and scatter their cargo over the fire. (web: http://www.flexiblealternatives.com/products/pcads). A similar system is the Israeli Caylym Guardian Deployment System (http://www.caylym.com/the-guardian/). In this case the containers are launched at some 1.500 feet AGL. 
The precision of the drop point achieved by a parachute without any form of guidance in an adverse atmospheric environment caused by wind, turbulence and the thermal currents produced by the ongoing wildfire, does not appear to be sufficient enough to produce a coordinated and efficient action of extinction. At the same time this concept entails that all the solid components, although biodegradable, will be spread all over the fire zone. It doesn't either permit night-time operation due to the low altitude demanded by the operation.

Another method proposed by Boing is that of using 'water bombs' (bomblets), a type of biodegradable dodecahedra shaped container filled with 50lbs of water (23litres). Using path-calculating systems, 2800 of these 'bomblets' would be launched via the rear ramp of a C-17 from between 1.000 to 2000 feet above the fire to drop freely, with no form of guidance whatsoever. (web:http://www.boeing.com/news/frontiers/archive/2003/august/i_ids4.html).

Assuming that the path calculating systems allow sufficient precision to allow the drop to occur within the designated zone, this would still imply that the impact of the bomblets, dropping at great speed in free fall onto the ground would in the first place result in a high risk factor for ground crews, people and possessions in the fire area. Secondly, the water would on impact extinguish some of the fire but the effect would not be optimal since the always desired atomisation of the water never occurs, therefore the amount of energy absorbed is highly reduced, implying a big reduction in the extinguishing effect.

This concept, as with the two previous ones, is also not applicable to night-time operations because of low altitude flying. Should the altitude be raised to a 'safe altitude' the precision of the drops would decrease and the risk factor increases because of the higher speed at impact of the 'water bombs'.

\section{The NITROFIREX concept}

The developing technologies in the control and guiding of UAV's allow for the development of innovative operational options such as the possibility of 'spraying' (a liquid) or 'scattering' (a powdered solid) an important amount of extinguishing agent from a programmed point in the atmosphere.

This is the case of NITROFIREX, an innovative project that integrates the industrial technologies of the Defence Force in order to attain an operative capability that could be applied in the battle against wildfires, to combat against an atomic, chemical or biological emergency, to operate with meteorological phenomena (inducing rain, avoiding hail, dissipating fogs), to fight against plagues or to sow in remote or inaccessible regions and also the fumigation of drug plantations at night.

Discarding all these possible applications, and due to the ecological harm caused, the social alarm generated as well as the human and economic losses that they bring forth, the project that NITROFIREX is developing with maximum priority is the one to combat wildfires. For that very reason NITROFIREX is concentrating on its night-time operations as an indispensible and necessary complement to aerial means already in use during daytime.

Heavy transport planes will be responsible for moving great quantities of useful cargo (extinguishing agents in the case of wildfires) to the operative zone. These planes are designed to transport at great speed big quantities of cargo at a cost per unit far lower to that of a smaller plane.

This is the NITROFIREX proposal: Launcher Aircraft, LAs (the heavy transport aircraft equipped with a rear ramp) will be employed to transport the NITROFIREX Airborne Glider Containers, AGCs (already containing \pm 2.500 litres of payload) to the programmed drop zone. See figure number 1 .

The LA will then launch the AGCs from the rear ramp in a programmed sequence and immediately return to the operation base. Once released, the AGCs will automatically home in onto their programmed target area within the drop zone and, with great accuracy, drop their load in the core of the fire. Once the drop of the fire-extinguishing agent on the fire has taken place, these containers return to base performing an "escape" manoeuvre from the danger zone by taking advantage of the great and sudden loss of weight as well as the extra speed. 

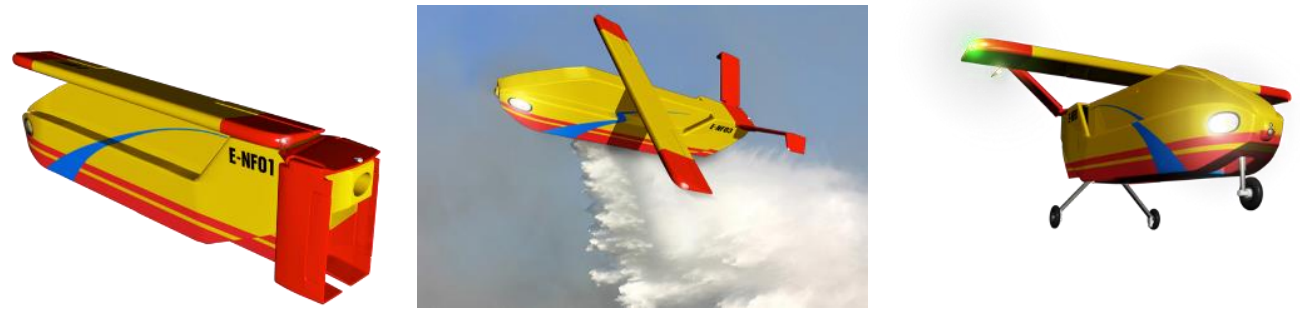

Figure 2

Then the empty NITROFIREX AGC begins its autonomous return to the operations base of the launcher aircraft where it can be swiftly reused and loaded into the LA thus beginning a constant turnaround operation until sunrise.

\section{The NITROFIREX Project}

Although, as we have seen in the previous paragraph, the concept has a wide application, NITROFIREX is, first and foremost, a completely innovative project focused on night-time aerial wildfire fighting.

As we have seen, the main element used is the NITROFIREX AGC, launched at medium altitude (six to ten thousand feet), from the rear ramp of the cargo bay of a heavy transport aircraft, such as the C130 Hercules, AN-12, KC-390, A400M, IL-76, C-17 or even aircraft with greater cargo capacity, which perform as the LA (launcher aircraft). These containers, loaded with a fire-extinguishing agent, are capable of gliding in their initial phase and are equipped with a guidance system (satellite, inertial and infrared). They fly automatically into the fire zone and drop their load, in sequence and with great accuracy, on the targeted area.

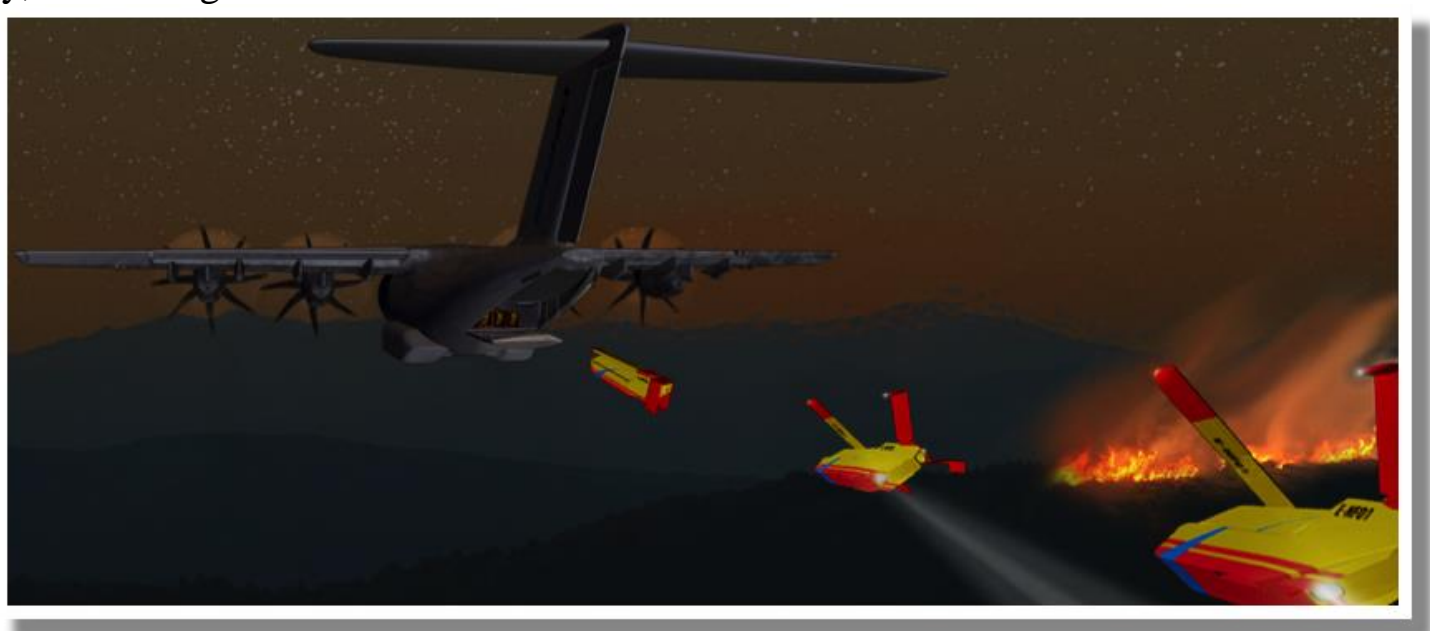

Figure 3

For safety, but also economic reasons, the NITROFIREX AGC's (Glider Containers) are recoverable. Once the drop of fire-extinguishing agent on the fire takes place, the NITROFIREX AGC performs an escape manoeuvre from the danger zone. Taking advantage of the great and sudden loss of weight as well as the surplus speed, the empty glider container is transformed, thanks to the activation of the small engine that propels it, into an UAV and returns autonomously to the operation base of the launcher aircraft where it can be swiftly reused.

In its guided bomb role the glider container flies no more than 90 seconds from the launcher aircraft to its target over the fire. When compared to a guided bomb, it carries a bigger payload and has more wing surface and but with an equal gliding and guide capacity. After concluding its 'escape' from the 
target area and until it lands at the launcher aircraft's operation base, it navigates at night as a UAV at 1,000 feet above ground level and attains speeds of up to $70 \mathrm{Kts}$.
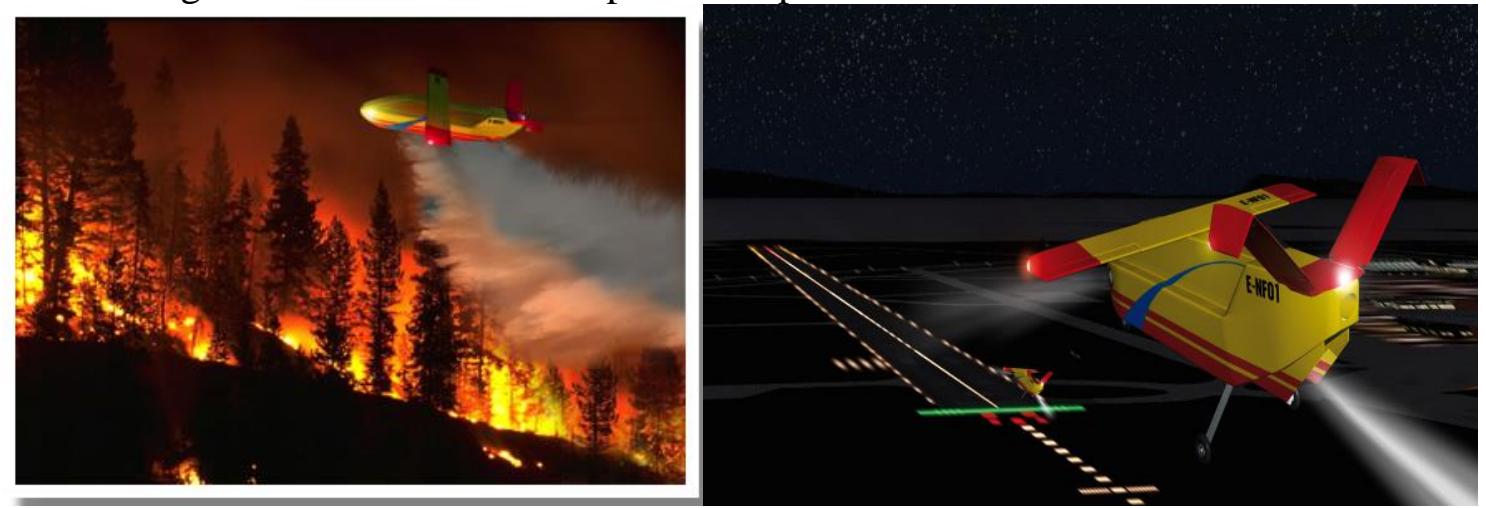

Figure 4

By no means does NITROFIREX want to substitute current aerial means whose efficiency in daytime operations has been demonstrated over decades. The truth is that NITROFIREX aims to be their nighttime counterpart in order to achieve H-24 aerial combat against wildfires ( 24 hour non-stop fighting) and to make use of, as the toiling ground crews well know, the better weather conditions that the night usually has to offer. In the following graphics one can analyse these advantages from:

1. The operative point of view (litres launched per hour of the operation),

2. The economic point of view (litres launched per hour and flight plus the cost of each litre launched)

3. The development of the NITROFIREX concept according to the type of AL used.

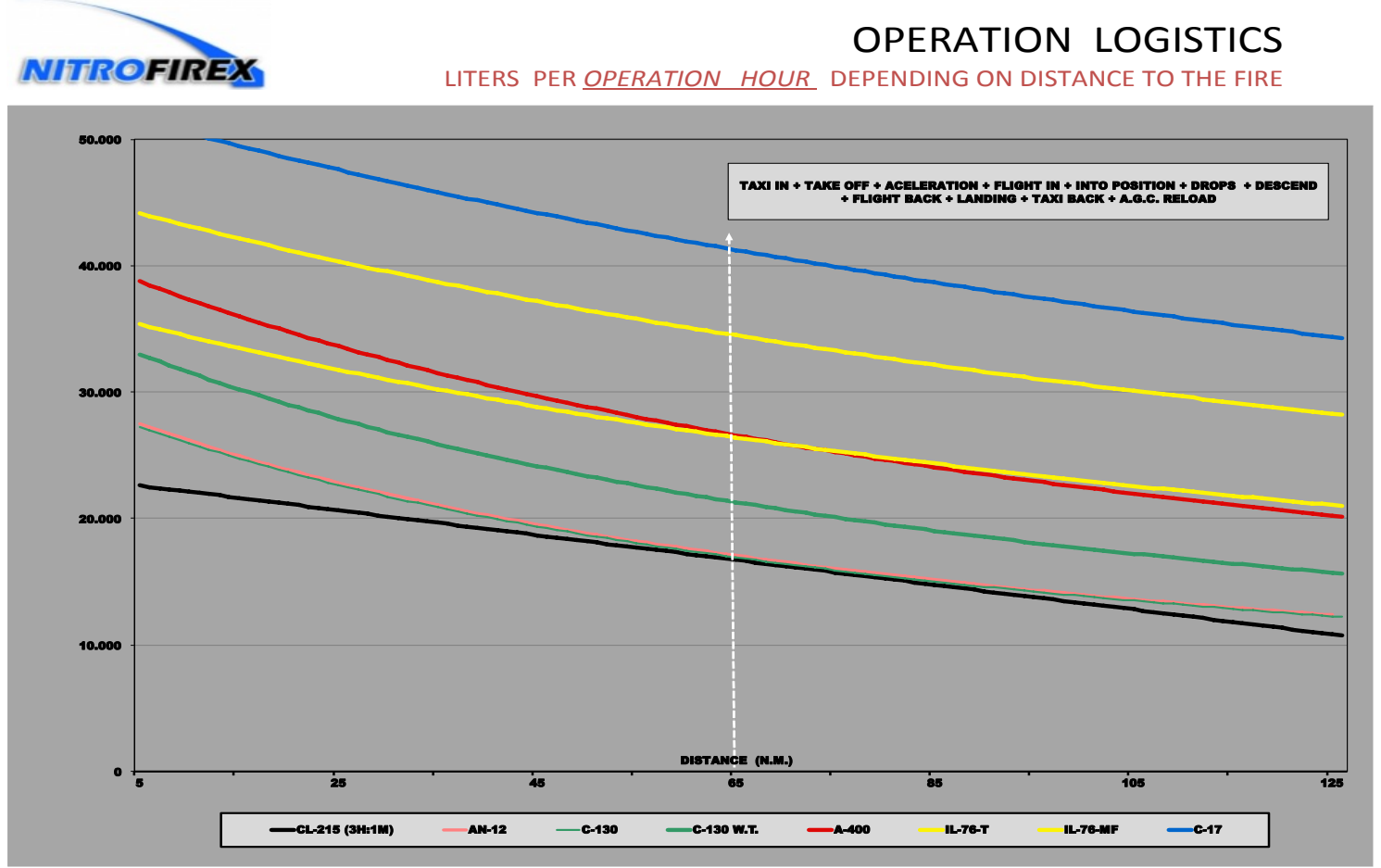

Figure 5 


\section{NITROFIREX}

OPERATION LOGISTICS

DROPPED LITERS PER FLIGHT HOUR DEPENDING ON DISTANCE TO THE FIRE

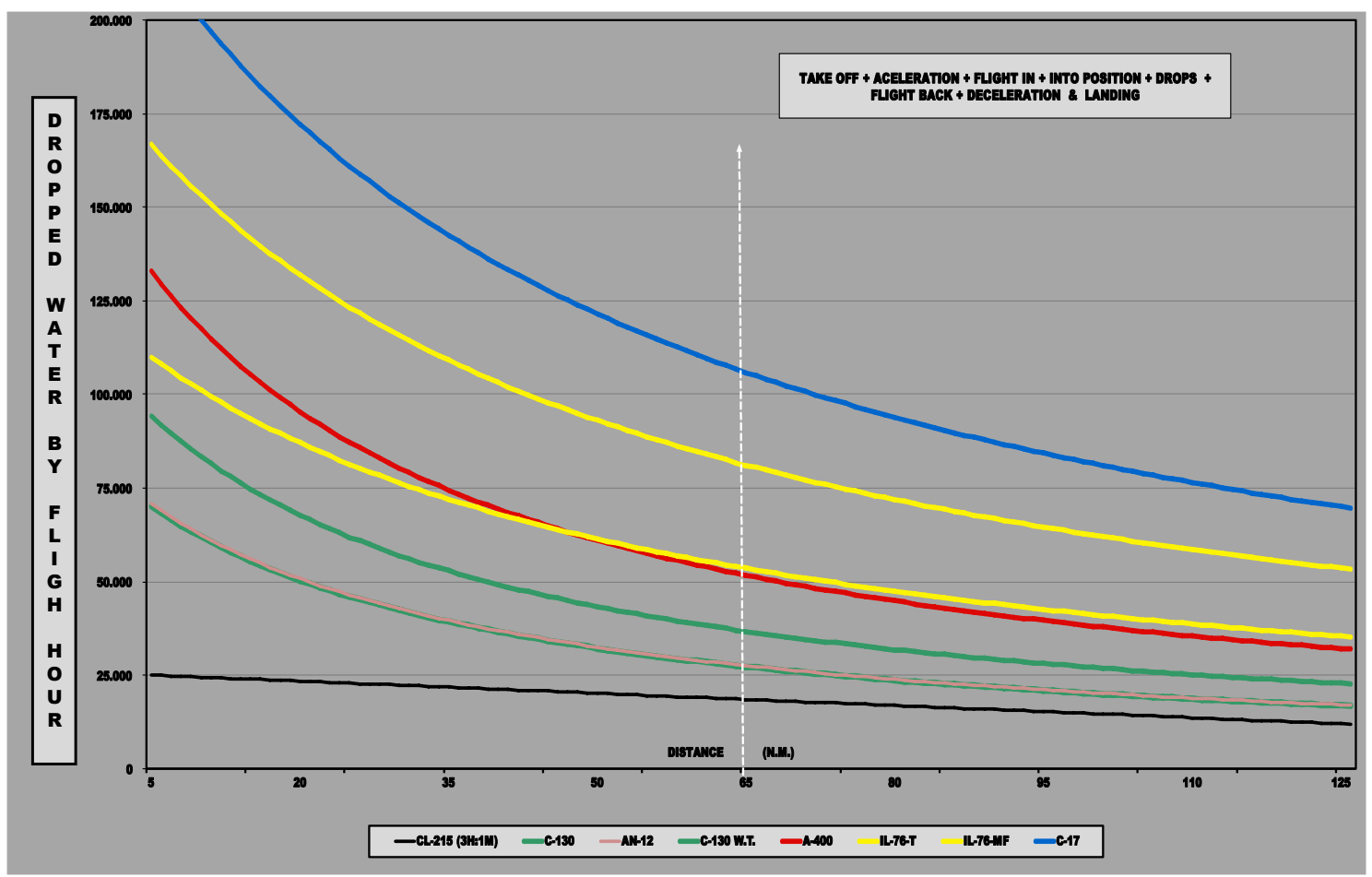

Figure 6

\section{OPERATION LOGISTICS}

\section{NITROFIREX}

DROPPED LITERS COST DEPENDING ON DISTANCE TO THE FIRE

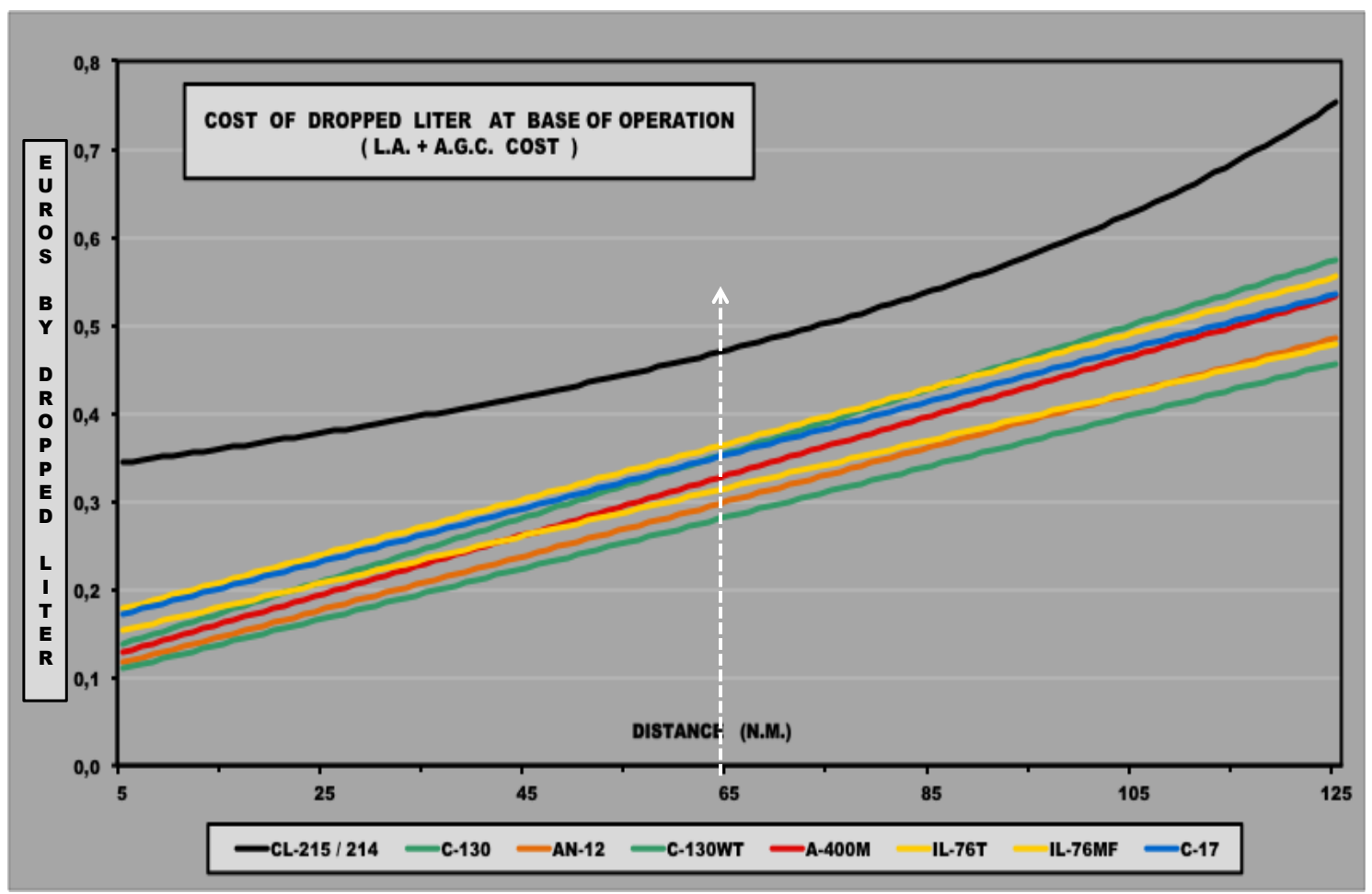

Figure 7

Advances in Forest Fire Research - Page 1472 


\section{Operational model}

Because of the great cargo capability and the increased deployment speed that the NITROFIREX LAs offer, a new operational model will have to be put into use. This will include a regional operational base that could be situated in a strategic site in accordance to the operations area.

Should a supranational operation come to be, the ideal base that would cover, for example, the Mediterranean Basin, would be Marseille in France or Olbia in Sardinia. Since the NITROFIREX operation is nocturnal, we can assure that under normal conditions, at least half a day would be needed to detach the LA to any airport in any country within the Basin.

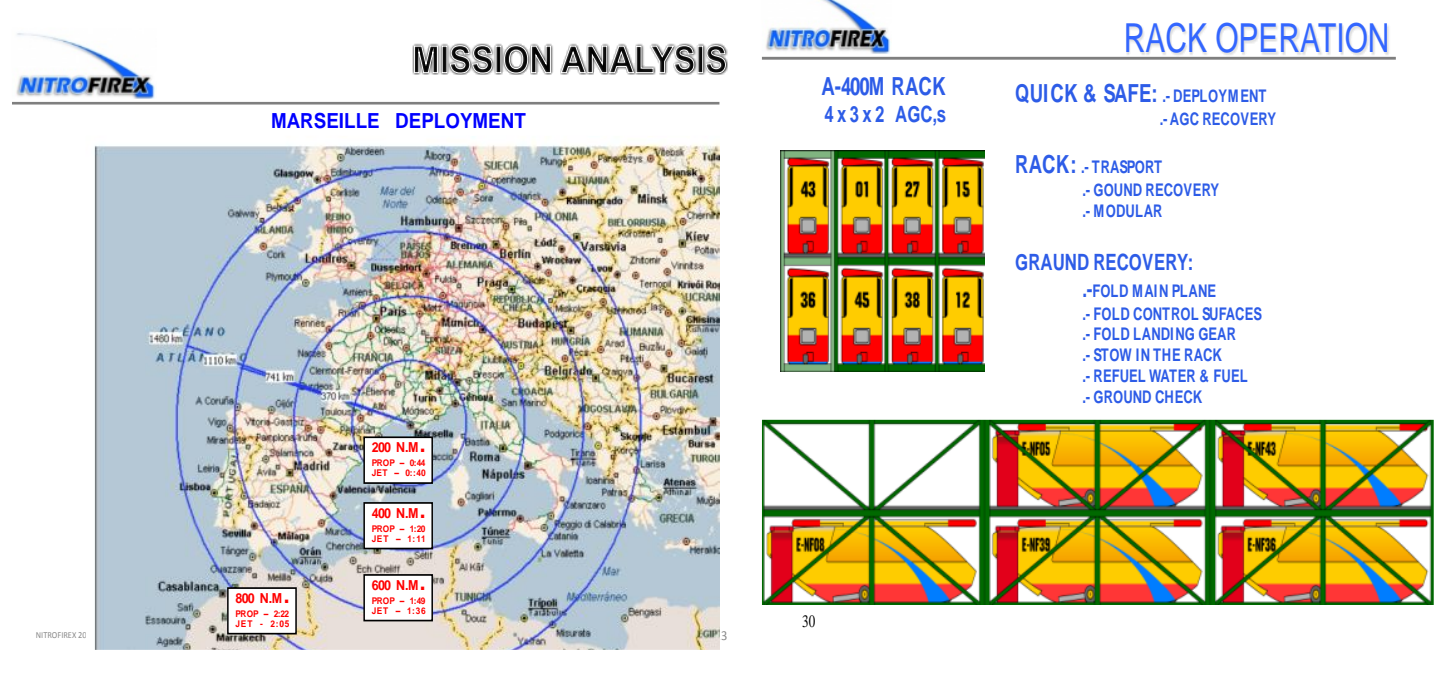

Figure 8

The NITROFIREX AGCs are transported from the regional operational base to the mission base (airport, air base or aerodrome closest to the fire). Two sets of empty NITROFIREX AGCs are stacked on two levels in a 'rack' or specifically designed shelving in the cargo hold of the LA. Later, during the mission this 'rack' will be used for the fast turn-around (pre-flight check, fuelling, loading of extinguishing agent and re-stacking) of the AGCs returning from the fire zone.

Once a wildfire alarm has been activated, the LA fly from their regional base to the detachment base, the airport closest to the fire, where the operation begins by downloading the rack of empty NITROFIREX AGCs and the rest of the necessary equipment so as to proceed with the final preparation. The first set of NITROFIREX AGCs (on the lower level of the 'rack') are filled with the extinguishing agent and are once again stacked in the LA leaving them ready for take off at dusk.

As night falls they fly to the fire zone and, coordinated by the ground teams who provide direct support, the LA begins launching the NITROFIREX AGCs in groups with a $90^{\circ}$ 'angle off' to the fire front the goal being that at the moment of leaving the LA the DPA's make a $90^{\circ}$ turn, so that when the 4 or 6 NITROFIREX AGCs leave the LA they can form up in a trail formation and attack the fire. The extinguishing agent is dropped over the area preselected by the fire management officer. In order to maximize the extinguishing effect the drops are overlapped.

Once the first set of NITROFIREX AGCs have left the LA, it returns to base to load the second set of NITROFIREX AGCs so it can then return to the fire area in order to continue the attack on same fire or to attack more than one fire simultaneously. The NITROFIREX AGCs autonomously return to mission-base after each drop.

For example, one could consider an operation of an A-400 with a cargo capacity of 12 full DPA's. Flying to the mission-base with a 'rack' holding 24 empty containers, it starts operating at dusk and launches in each flight 12 containers filled with the extinguishing agent and rapidly returns to load the next 12. In the case of the A-400 the cargo load of each DPA would be 2,583 litres, which 
means that a single flight of an A-400 would be approximately equivalent to 6 drops of the Canadair CL-215/415. At a distance of $120 \mathrm{~km}$ (65 N.M.) between the mission base and the fire zone an A-400 can perform 9 flights in one night dropping 12 DPA's with each flight.

According to operative analyses done by NITROFIREX, and assuming the loading and stowage coefficients for the NITROFIREX AGCs, one can establish that having one LA and its two sets of NITROFIREX AGCs detached to a mission base within $120 \mathrm{~km}$, the operation over the fire zone would be non-stop. The LA turn-around at mission base for loading the NITROFIREX AGCs would ensure a relentless dropping of water over the intended targets. See graphics number 4 and number 5 .

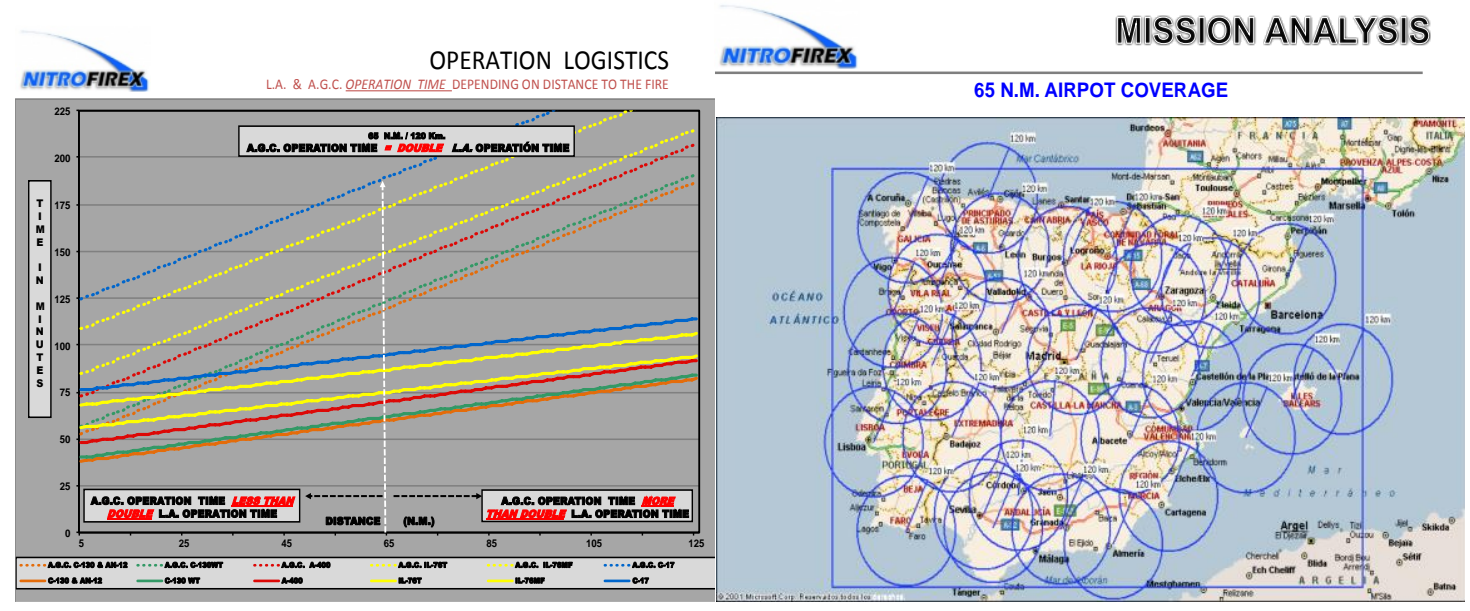

Figure 9

\section{Drop optimization}

Present day aerial resources used in fighting wildfires manually execute the drops of extinguishing agent directly over the fire, to either extinguish or to cool down the zone. So the effectiveness and efficiency of a drop depends on the pilot's, as well as the fire management officer's experience and ability.

If the drop is performed at an excessive height, the water is atomized by the fall and because of thermal convection it does not manage to reach the core of the fire thus greatly diminishing the effectiveness of the release. Conversely, if the release is excessively low the water reaches surface still compacted, without atomizing sufficiently. Here it evidently achieves some success but does not reach its full potential.

But if the drop is done at the ideal height most of the atomized water reaches the core of the fire. The maximum transfer of energy is obtained between the fire and the water. The resulting dowsing action of the water mass on the fire can be considered to be ideal.

Therefore we face the problem of drop optimization, which to date has not yet been studied. One has to find the exact point where, during the drop, water atomization allows water droplets of the smallest possible diameter to reach the fire surface, therefore favouring the heat exchange between the agent and the fire.

The fundamental factors for optimizing the release are the height above the ground and the speed of the aircraft/glider container at the point of water release. Relying on these two essential parameters, it is possible to optimize the minimal size of the drops landing on the ground depending on the desired launch strategy.

There are other parameters to be taken into consideration at the moment of optimizing the release. These are the diving angle at the moment of the release and the use of a thickener to change the surface tension of the water at the planned high-speed release from the glider containers so as to control the 
minimum size of the droplets at the moment of the impact and thus obtaining a higher capability of penetrating the core of the fire.

In the NITROFIREX project the release from the NITROFIREX AGC will be completely automatic. The research on release parameters (height, speed, diving angle and surface tension) must be undertaken in order to obtain the maximum efficiency from the release.

The release of a considerable mass of water (thousands of litres) from an air vehicle (plane, helicopter or glider container) at a relatively high speed can be studied initially from a theoretical point of view as a problem of fluid dynamics in order to establish a mathematical model that will assist in establishing the ideal parameters of the release.

The idea consists of establishing a simplified model in order to optimize the operation. It is necessary to bear in mind that it is a question of a two-phase flow (air - water), turbulence and having different parameters within the same plume of water. These, the main parameters that determine the nature of the problem, are the dimensionless numbers of Reynolds (turbulence) and Weber (effects of the surface tension), which can be considered infinite to practical effects in the exit area or water door of the glider container.

The subject of the release can be split into several areas ranging from the NITROFIREX AGC to the ground. The first area can be considered of potential flow, just at the exit of the glider container. It is followed by an area where a primary atomization takes place, where droplets of the smallest diameter are obtained. An area starts then to configure where a Rayleigh-Taylor instability prevails after which an area comes forth where a secondary atomization takes place, where you can find droplets increasing in size due to the decrease in the speed of the water plume. Knowing parameters such as speed, height and dive angle, it is possible to estimate an average or statistical distribution of the size of the drops, therefore allowing to adjust this distribution so as to perform each release in the most effective way, under any given conditions.

The study for the optimization of the release is a process requiring both basic research in fluid mechanics and applied research that could also be of great help in improving conventional means of operation.

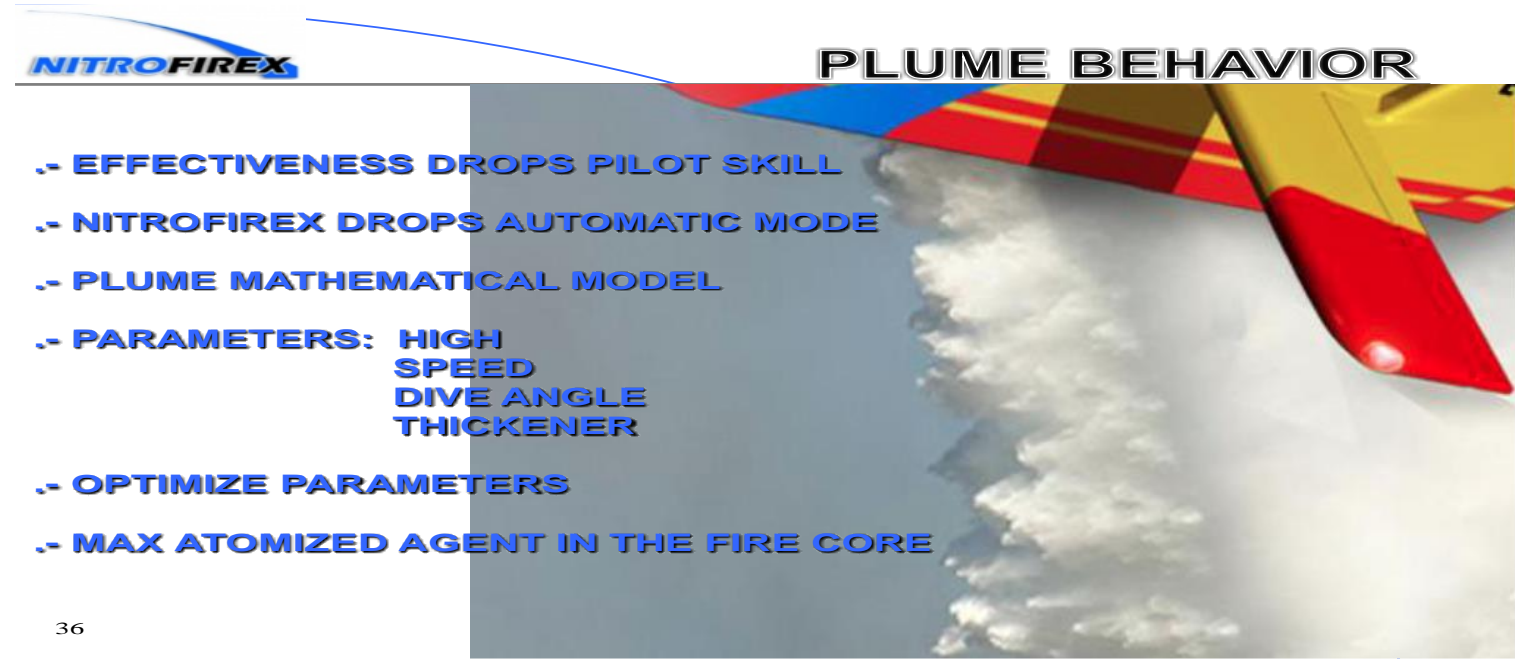

Figure 10

\section{Coordination and safety}

Those dedicated to aerial fire fighting know the importance of ground/air coordination to ensure an efficient and safe operation. With this objective in mind NITROFIREX proposes the implementation of new operative protocols and rules of communication with ground crews that are needed to adapt to the requirements of this project. 
It should be the fire management officer who maintains radio contact with the LAs and the missionbase to coordinate the whole operation, principally the waiting points of the LAs as well as the approach routes and drop points of the NITROFIREX AGCs.

At night it becomes very important that the ground crews can see the approach and the drop from the NITROFIREX AGCs. For that reason, apart from the standard lights of all aerial vehicles (navigation, beacon, strobe and logo lights), the NITROFIREX AGCs are equipped with lights illuminating the fuselage as well as powerful headlamps. These headlamps are aimed forwards so that ground crews will be able to see them in the far distance and calculate the speed of approach to the drop point. So, ground crews will be able to very clearly see the approach, the actual drop and its effect on the fire as well as the NITROFIREX AGCs departure from the drop point.

In any type of aerial operation safety is of primordial importance at the time of planning, something NITROFIREX is not indifferent to. Consequently the NITROFIREX AGCs in their approach to the drop as well as in the recovery phase to mission base will have their flight parameters programmed and will accomplish them automatically and autonomously. But the safety concept of 'a man in a loop', in the case of having to abort the drop or reprogram the recuperation route, has been considered fundamental for the safety of the operation.

Therefore, during the approach phase, the NITROFIREX AGCs will be capable of manually or automatically aborting their approach to the drop point, releasing their cargo at the abort point and then proceeding automatically into the escape and recovery phase. Should the flight trajectory deviate from the one established or an unexpected event occurs during the approach to the drop point and it becomes advisable not to continue, the abort can be manual, carried out by the NITROFIREX AGCs operators at mission-base or from the LA and decided by anyone of them or by the fire management officer. The NITROFIREX AGC can automatically abort if its flight path does not match with what had been programmed or if it approaches the ground and/or a non-desired location.

In any case, the NITROFIREX AGC never reaches the ground filled with extinguishing agents, because if any thing deviates from what was programmed the cargo is immediately released and it then moves into the recovery phase.

On the other hand, the return route of the NITROFIREX AGCs to mission base will be programmed for the night (they have all day to do it in), at 500ft or less and over uninhabited areas. Should, by chance, the NITROFIREX AGCs engine have a flameout or any other malfunction during the return it is equipped with a parachute and an airbag, which opens up automatically and that allows for a 'soft landing', minimizing any possible damage.

\section{Technical regulations for the operation of UAV's}

Today the great stumbling block in operating UAVs in purely civilian aerial operations is the lack of rules and regulations controlling the airspace where both manned and unmanned aircraft could operate. For promoting the development of such rules and regulations at an international level two basic kinds of operations have been established: VLOS and BVLOS.

VLOS are those UAVs that operate in 'Visual Line of Sight' conditions, that is to say that at all moments there is visual contact between the vehicle and the operator. The operator's responsibility is to avoid any situation that could endanger any other aerial vehicle (manned or unmanned) or persons or properties on the ground. International regulation of UAVs operating within VLOS is meant to be available by 2015 since no technical or regulatory drawbacks exist, the operator being solely responsible for the safety of the vehicle.

BVLOS are those UAVs that operate under conditions 'Beyond Visual Line Of Sight', that is to say that in given distances and altitudes required for its employment the operator loses sight of the vehicle whilst electronic control is still maintained. These UAVs tend to have a great range and normally require the same airspace and altitudes of operation of manned aircraft. 
Therefore regulating BVLOS UAVs is more complex, entailing greater technical requirements that will be needed because of the new players involved. These players range from the UAV operator to the air traffic controllers as well as the pilots of the manned aircraft.

Logically NITROFIREX stands in the second group of UAVs that operate under conditions of 'Beyond Visual Line Of Sight'. But the airspace required by the NITROFIREX project is in fact minimal: A segregated airspace over of the fire would be used for an LA flying at an altitude no more of 6.000 feet and a distance of no more of $6 \mathrm{NM}$ in respect to the intended drop zone. The LA will launch the NITROFIREX AGCs that would need no more than 90 seconds with their filled tanks, and finally no more than an hour of navigation at an altitude of 500 feet between the fire and the mission base (the LA operating base).

What manned aircraft could be flying in the proposed zone? That is to say a zone at an altitude of 500 feet or less between a fire and the LA's mission base? It is for this very reason that a night-time operation is proposed, so that the regulations established could serve as a stepping stone for future operational regulations for UAVs in a civilian environment that need more flight time and airspace for manoeuvres.

Understanding the flight envelope proposed, and in context with the BVLOS regulatory authority, the profile of the NITROFIREX AGCs recovery as proposed by NITROFIREX should be the first to be regulated because the operational hours and the airspace required cannot affect manned traffic. This would serve the use of UAVs in a safe and secure manner within the civilian environment of the BVLOSs. At the same time, it may take advantage of using it as a 'launching pad' for future regular BVLOS operations in the upper layers of airspace where safety requirement and coordination are far superior owing to the altitudes and flight times needed for UAV operations.

In one word, if in a BVLOS operation the low altitude profile, as proposed by NITROFIREX, is not regulated and it will be extremely difficult to regulate profiles requiring higher altitudes and longer time spans.

\section{The aeronautical industry and UAV's}

In the emerging and promising world of UAV's, aeronautical businesses as well as different governments and organizations are vying for good places in this race for the civil \& military market of the future that unmanned air vehicles can provide.

The aeronautical industry and her official organizations will participate in this race with different products and business initiatives. But, owing to the on going economic crisis and the lack of rules and regulations, the short and medium future of the UAV's in our country is a singular challenge.

In addition to the profound economic crisis in which we are at present immersed, the defence and social security budgets are the first to be cut and readjusted. So, at the present moment, the UAV industry has to resort to ecological projects and appeal for social and political support to be able to support its participation in the development of the emergent world of unmanned aerial vehicles. The expensive and more complex projects must wait for better times.

Regarding past circumstances and now facing actual circumstances, the approach should be to find low cost projects operating in 'marginal airspace' with the purpose of keeping the regulatory bodies to a minimum.

The NITROFIREX Project entails all the previously mentioned connotations. As an air vehicle, it must obviously fly -both in the glider phase as well as in the UAV phase. Of course the NITROFIREX AGC must be able to navigate and release its cargo as programmed. One could propose an aircraft or a high performance aerodynamic vehicle or high performance aeronautic vehicle that would be evaluated, developed and whose final cost would never reach that of other projects with more demanding technical and operative objectives.

In addition to, and taking into account present circumstances, it should be the responsibility of the organizations and businesses involved in the development of the UAV's to refer to the economic 
losses, the political concern and the social fear that wild-fires generate, in order to obtain economic aid and above all political aid that a project of this nature needs for its development.

Given its relatively simple technique and minimum requirements when compared to the other UAV projects, the NITROFIREX project can and should be dealt with solely aeronautical industry, instead of having to resort to complex and problematical international alliances. In these difficult times this would allow companies to find a niche in the complex and competitive world of unmanned aerial vehicles, serving at the same time as a launching pad for the aeronautical industry to find a good position within the UAV world by the time the civil employment of these vehicles becomes standard. NITROFIREX has been presented in Madrid at the Spanish summit of unmanned vehicles, UNVEX12 and at the Defence and Security Fair HOMSEC13. In both cases, great interest was shown amongst the official organizations (Spanish and European) as well as private businesses in this sector, especially regarding the exclusive and original approach on the operative and technical levels of the project.

During these two fairs it was obvious that the greater majority of UAV's are conceived for military or paramilitary employment. Consequently they are designed to transport technology composed of sensors and/or cameras with the object of obtaining and/or transmitting information. In order not to be detected or seen they are un-illuminated and are painted in discreet colours.

On the contrary the NITROFIREX AGCs are designed primarily for civil employment and conceived to spray/dust large quantities of non-technological substances at a programmed point of the atmosphere. In order to be seen by all involved in the operation they are illuminated (night flight) and painted in striking colours or marked by smoke generators (day flight).

Likewise, NITROFIREX's presentation at the International Aerial Fire Fighting Meeting in Aix en Provence (Marseille-France) April 2013 and in Sacramento March 2014 awoke enormous interest amongst the international aeronautic community for wildfire fighting. Our presence in the regulatory aspect brought us to give another speech in Eurocontrol in Brussels.

The importance and the concern of night-time fighting was obvious. The need to confront wildfires with security and efficiency is the great operational lack in of aerial means, a shortcoming and a total disregard for its importance!

The NITROFIREX Company has developed the conceptual phase of the project at its technical level as well as the operative and economic levels. It is now in the phase of consolidating the agreements between industrial/technological associates so as to confront the first phase of the construction of a concept demonstrator and subsequently the development of the Project.

The NITROFIREX concept is patented in those countries which have an economic and aeronautic capacity to face this type of project and who also have serious wildfire problems such as the USA, Canada, Australia, the Russian Federation and Europe (Spain, France, Italy, Germany England, Switzerland and Sweden). In addition, NITROFIREX is a member of the European organization EUROCAE and leads the work-group GW93. This group is responsible for editing the rules pertaining to the first phase, a phase that regulates UAS flights in non-segregated airspace in Europe.

\section{Conclusions}

It doesn't make sense that, well into the XXI century, at a time when ecology in all its aspects (climate change, $\mathrm{CO} 2$ emissions, deforestation, etc.) becomes a red hot topic on the political, social and economic levels, we've not bothered to integrate these demands in order to combat forest fires by night.

The use of an autonomously guided glider container, such as the one proposed in the NITROFIREX Project, allows for nocturnal aerial fire fighting operations, eliminates risks for crews and increases the accuracy and concentration of the releases. Besides all this, the amount of water dropped both per operating hour and per flight hour is increased with respect to the aerial methods currently used. In addition, the launcher aircraft to be used are large military transport airlifters that are not single-role and they will continue performing cargo operations for the rest of the year once the summer forest fire 
season is over. This will help bring down to a great extent the final flight-hour cost (considering acquisition amortization in addition to maintenance, personnel, etc.) for the part of operations performed on fire fighting, and ultimately the cost of each dispatched litre.

The new technologies have already been developed, matured and made available. It is only necessary to integrate them towards the objective that concerns and worries us. It is therefore up to the politicians and technicians in charge of the operation to accept the seriousness of the problem and to raise a new strategy against the ecological damage, the economic loss and the social alarm that forest fires produce. It is high time for the managerial and academic worlds to take on the challenge that an R\&D project of this nature and relevance imposes.

The challenge consists in daring to develop this technological integration here and now with political decision, managerial initiative and technological drive. 